\title{
Photochemistry on the Space Station-Aptamer Resistance to Space Conditions: Particles Exposure from Irradiation Facilities and Real Exposure Outside the International Space Station
}

\author{
Coussot Gaelle ${ }^{1,}{ }^{*}$, Le Postollec Aurelie ${ }^{2}$, Incerti Sebastien ${ }^{3}$, Baque Mickael ${ }^{4}$, Faye Clement ${ }^{5}$, \\ Vandenabeele Trambouze Odile ${ }^{6}$, Cottin Herve ${ }^{7,8}$, Ravelet Corinne ${ }^{9}$, Peyrin Eric ${ }^{9}$, \\ Fiore Emmanuelle ${ }^{9}$, Vigier Flavie, Caron Jerome ${ }^{10}$, Chaput Didier ${ }^{11}$, Przybyla Bartos ${ }^{12}$, \\ Berger Thomas ${ }^{12}$, Dobrijevic Michel ${ }^{2}$
}

1 Univ Montpellier, ENSCM, CNRS, IBMM, F-34093 Montpellier 5, France.

2 Univ Bordeaux, B18N, CNRS, LAB, Pessac, France.

3 Univ Bordeaux, UMR 5797, CENBG, Gradignan, France.

${ }^{4}$ German Aerosp Ctr DLR, Inst Planetary Res Management \& Infrastruct, Res Grp Astrobiol Labs, Berlin, Germany.

${ }^{5}$ Colcom, Cap Alpha, Clapiers, France.

6 UBO, LMEE, IUEM UMR 6197, Plouzane, France.

7 Univ Paris Est Creteil, UMR 7583, LISA, Creteil, France.

8 Univ Paris Diderot, Inst Pierre Simon Lapl, Creteil, France.

9 Univ Grenoble Alpes, Dept Pharmacochim Mol, CNRS, UMR 5063, St Martin Dheres, France.

${ }_{10}$ Comprehens Canc Ctr, Inst Bergonie, Dept Radiotherapie, Bordeaux, France.

${ }^{11}$ Ctr Natl Etud Spatiales, DCT ME EM, Toulouse, France.

12 German Aerosp Ctr, Inst Aerosp Med, Cologne, Germany.

* Corresponding author : Gaelle Coussot, email address : gaelle.coussot@umontpellier.fr

\begin{abstract}
:
Some microarray-based instruments that use bioaffinity receptors such as antibodies or aptamers are under development to detect signatures of past or present life on planetary bodies. Studying the resistance of such instruments against space constraints and cosmic rays in particular is a prerequisite. We used several ground-based facilities to study the resistance of aptamers to various types of particles (protons, electrons, neutrons, and carbon ions) at different energies and fluences. We also tested the resistance of aptamers during the EXPOSE-R2 mission outside the International Space Station (ISS). The accumulated dose measured after the 588 days of this mission ( $220 \mathrm{mGy}$ ) corresponds to the accumulated dose that can be expected during a mission to Mars. We found that the recognition ability of fluorescently labeled aptamers was not significantly affected during short-term exposure experiments taking into account only one type of radiation at a time. However, we demonstrated that the same fluorescent dye was significantly affected by temperature variations $(-21$ degrees $\mathrm{C}$ to +58 degrees $\mathrm{C})$ and storage throughout the entirety of the ISS experiment ( $60 \%$ of signal loss). This induced a large
\end{abstract}


variability of aptamer signal in our analysis. However, we found that $>50 \%$ of aptamers were still functional after the whole EXPOSE-R2 mission. We conclude that aptamer-based instruments are well suited for in situ analysis on planetary bodies, but the detection step requires additional investigations.

Keywords : Astrobiology, Cosmic rays, Biochip, Aptamers 


\section{Introduction}

In the context of planetary exploration, space agencies call for the development of miniaturized techniques to search for traces of extant or extinct life. In particular, the use of instruments based on bio-affinity receptors, like antibodies or aptamers, might be very efficient. In this technology, bio-affinity receptors are fixed to a solid surface to specifically capture their target. A signal is displayed when receptor-target recognition events occur.

Antibody-based biochips have been extensively studied in proteomic and functional genomics and their scope has been extended to the field of astrobiology. Indeed, due to the benefits of high throughput and miniaturization, and small volume consumption, antibody-based biochips have been proposed to detect biomarkers, especially organic ones, in the search for extraterrestrial life (Parro et al., 2005; Le Postollec et al., 2007; Parro et al., 2008; Martins et al., 2011; Parro et al., 2011b; Sims et al., 2012; McKay et al., 2013; Smith et al., 2014). Space is a hazardous environment, with high fluxes of ionizing radiations, from primary particles of galactic cosmic radiation (GCR) and solar energetic particles (SEP), to secondary particles produced by the interaction of primary particles with environment materials. One main concern relies on the resistance of biochips to the cumulative effects of these radiations. In recent years, studies have been performed to evaluate the resistance of antibody reagents to space constraints, especially regarding the effect of specific particles on antibody binding performances (Le Postollec et al., 2009a; Le Postollec et al., 2009b; Baqué et al., 2011a; de Diego-Castilla et al., 2011; Baqué et al., 2017; Coussot et al., 2017). To complement ground-based radiation studies, a short term mission was performed on the BIOPAN-6 low-earth orbit platform to demonstrate the effects of cumulative radiations on the antibodies' ability to bind to their respective antigens (Derveni et al., 2012; Derveni et al., 2013). For the absorbed radiation doses during the 12 days of exposure, the freeze-dried antibodies packaged into laser-cut glass fiber pads were unaffected 
with regard to their recognition performances in the condition of the experiment. Furthermore, in the frame of the BiOMAS project (Biochip for Organic Matter Analysis in Space) and part of the Photochemistry on the Space Station (PSS) experiment, biochip models, in which antibodies were immobilized onto a surface, have been installed outside the International Space Station (ISS) on the EXPOSE-R2 platform, for a real long-term exposure (more than 18 months) to spatial constraints (Vigier et al., 2013; Cottin et al. 2015, Cottin et al. 2017). Our recent results show that our biochip models resist to an 18 months extra-vehicular mission (Coussot et al., 2018b). This work, in combination with the ground-based radiation studies, permits to assess the antibodies' ability to bind to their respective antigens even after a longterm exposure to the real space environment. These experiments indicated that antibody-based instruments seem well suited for the search for organic matter in in situ planetary bodiesô samples.

Other target-binding reagents with specificity and binding affinity rivalling with those of antibodies are aptamers. Aptamers are short, single-stranded nucleic acids, able to bind from small molecular weight molecules up to proteins. Aptamers have demonstrated some interesting advantages over antibodies: production at low cost, specificity against small and nonimmunogenic molecules, thermal stability, and ability to maintain their structures over repeated cycles of denaturation/renaturation (Song et al. 2012). From diagnostics to food safety or therapeutics, aptamers have shown their interests in arrays and biosensors development (Song et al. 2012; Dong et al., 2014; Rozenblum et al., 2016; Gotrik et al., 2016). The first investigation for nucleic acid aptamers ability to maintain their binding performances under simulated cosmic radiations, in particular $2 \mathrm{MeV}$ protons effects, was carried out by Baqué et al. (2011b). The results revealed that, under the protons flux and energy tested, there were no deleterious effects on the binding affinity of the irradiated DNA aptamer. So far, no more 
104 investigations on the effect of high-energy particles on aptamer performances have been 105 reported.

106 In the present study, we first present a set of experiments carried out these last seven years in 107 ground-based particles accelerator facilities to study the effect of different types of incident 108 particles (protons, electrons, neutrons, and carbon ions) at different energies and fluences, on 109 the ability of a model aptamer to recognize its target. The second part of the paper discusses the 110 results obtained after a long time exposure to real space constraints of aptamer samples in the 111 framework of the PSS project (Cottin et al., 2015). 


\section{Materials and methods}

\section{II.1 Chemical, reagents and materials}

$L$-tyrosinamide ( $L$-Tym), fluorescein dye $(\mathrm{F})$, sodium bicarbonate $\left(\mathrm{NaHCO}_{3}\right.$, Ó99,5\%), sodium carbonate $\left(\mathrm{Na}_{2} \mathrm{CO}_{3}\right.$, Ó99,5\%), and Tris(hydroxymethyl) aminomethane (TrisÓ99,8\%) were purchased from Sigma Aldrich (Saint-Quentin Fallavier, France). $\mathrm{NaCl}$ and $\mathrm{MgCl}_{2}$ of analytical grade were obtained from Chimie-Plus Laboratoires (Bruyères de Pouilly, France) and Panreac Quimica (Barcelona, Spain), respectively. The aptamer anti- $L$-Tym containing 49 nucleotides and modified in its 3ôend by fluorescein (\#4551724, MW $15860.5 \mathrm{~g} / \mathrm{mol}$ ) was provided by Eurogentec (Angers, France). This aptamer was chosen as an aptamer model, it has been reported as 49 merYm $3 \hat{\alpha}$ in the text, and had the following sequence

5ôAATTCGCTAGCTGGAGCTTGGATTGATGTGGTGTGTGAGTGCGGTGCCC-F-3ô (4 different batches were used: batch 1 for ground-based neutrons, electrons, and protons experiments, batch 2 for ground-based ${ }^{12} \mathrm{C}$ experiments, batch 3 for ISS mission; batch 4 for post-flight experiments). The ultrapure water (18.2 M $\Omega$ ) was obtained from a Purite Still Plus water purification system (Thame, UK). Other chemicals are analytical grade and used as received. Nunc MaxiSorpÊ polystyrene 96 well plates were obtained from VWR (France), and were used as sample containers during the freeze-drying step, and throughout the laboratory radiation exposures. In case of ISS experiment, Corning DNA BindÊ 8-well strip plate with N-hydroxysuccinimide modified surface (NHS-wells) were provided by Sigma Aldrich (SaintQuentin Fallavier, France). NHS-wells were manufactured by Air Liquide (Sassenage, France) to fit perfectly with the shape and size of EXPOSE-R2 closed cells provided by the French Space Agency (CNES, Toulouse) (Vigier et al., 2013). The home-designed NHS-wells had a diameter of $8.4 \mathrm{~mm}$ with a $7.1 \mathrm{~mm}$ height. Teflon cap were specially manufactured by Air Liquide to close the well. (Figure 1a) 
140 Particle irradiation effects were evaluated on both freeze-dried 49merYm3 $\hat{\sigma}$ F aptamer and 141 fluorescein dye. One hundred microliters of 49merYm3 $\tilde{\sigma} F$ aptamer or fluorescein solution at $142500 \mathrm{nM}$ in ultrapure water (dilution by $1 / 40$ from a stock solution freshly prepared at $20 \mu \mathrm{M}$

143 from aptamer commercial vial) were put into MaxiSorpÊ wells (commercial or home-designed well format) and freeze-dried according to a protocol optimized for the freeze-drying of small volume of reactants (Coussot et al., 2018a). Briefly, MaxiSorpÊE wells were put into a homemade aluminium holder, and liquid nitrogen was added to freeze the samples. The aluminium holder was then placed into the central part of a freeze-dryer with a top-press device (Christ Alpha $2 \ddot{i} 4$ from Martin Christ GmbH, Germany). Freeze-drying was performed overnight (condenser temperature $\overline{1} 85^{\circ} \mathrm{C}$, vacuum 0.05 mbar). The chamber of the freeze-dryer was filled with nitrogen gas before closing the sample-containing aluminium holder, which kept sealed hermetically the samples and sheltered them from the moisture and light until its opening. The opening of the aluminium holder was done in a glove box under a controlled atmosphere of helium $(10 \% \mathrm{He})$ in argon (Ar) provided by Air Liquide (Sassenage, France) to maintain a relative humidity (RH) level of 10 to $15 \%$. During our experiments, the $\mathrm{RH}$ and air temperature were controlled using a thermohygrometer Testo $605-\mathrm{H} 1$ (Testo, France). RH was $12 \pm 3 \%$ and air temperature was $22.8 \pm 2.3^{\circ} \mathrm{C}$. After opening the aluminium holder, freeze-dried samples were sealed within a plastic bag using a vacuum sealing device FoodSaverÊ (Fischer 158 Scientific, France) and stored at $4^{\circ} \mathrm{C}$ in the dark until running laboratory irradiation experiments.

In case of ISS experiments, $150 \mu \mathrm{L}$ of carbonate buffer ( $\mathrm{pH} 9.4,0.1 \mathrm{M}$ ) were added into the home-designed NHS-wells to deactivate reactive sites. The incubation took place overnight at 
room temperature. After successive water washings, $100 \mu \mathrm{L}$ of $49 \mathrm{merYm} 3 \hat{\widetilde{F}}$ aptamer/fluoroscein solution at $500 \mathrm{nM}$, freshly prepared in ultrapure water, were pipetted into each well. The freeze-drying procedure was run as described above. After opening the

165 aluminium holder in the above controlled atmosphere, freeze-dried samples were capped and directly transferred into the CNES closed cells using a tool vacuum suction pen (FFQ939 from Mayf's Online Shop, China). The CNES closed cells were then screwed with a final tightening of $0.7 \mathrm{Nm}$ using a torque screwdriver TorqueVario ${ }^{\circledR}-\mathrm{S}$ (Wiha, Germany) (Figure 1b) (Vigier et al., 2013). Soldering of the CNES cells and their integration to the sample carriers were done according to CNES internal procedures.

\section{II.3 Experiments on ground-based particles accelerator facilities}

The composition of cosmic rays is dominated by protons, electrons, alpha particles, and a small fraction of heavy ions (like carbon, oxygen and up to iron ions). Interactions of these primary particles with matter produce secondary particles like electrons and neutrons. So, experiments on ground-based facilities (producing protons, electrons, neutrons and carbon ions) have been performed to study the impact of GCR and SEPs on the affinity of the 49merYm3 $\hat{\alpha}$ F aptamer towards its $L$-Tym target. The set of experimental conditions is summarized in Table $\mathbf{1}$, and detailed in Baqué et al., 2017. These are considered as short-term exposure experiments taking into account only one type of radiation at a time to study the potential effects on the 49merYm3 $\tilde{F}$ aptamer- $L$-Tym bindings. All experiments were repeated at least 3 times per irradiation conditions in order to have 3 titration curves per analytical conditions. 6 replicates were prepared for fluorescein dye. Freeze-dried samples were irradiated directly in their sealed bags. The influence of the bag during irradiation experiments was simulated with GEANT4 Monte Carlo toolkit and demonstrated to be negligible (Baqué et al., 2017). Controls are the reference samples that have been freshly prepared the day of analysis: they did not undergo 
freeze-drying process, neither transportation nor storage at $4{ }^{\circ} \mathrm{C}$. We previously verified that freeze-drying does not induced any effects on binding curves nor in $K_{d}$ value. So, controls (freshly prepared references) can be used in place of lyophilized-non-irradiated samples for ground-based experiment interpretations. Analyses were done by using fluorescence polarization (FP) assay for aptamers as described in section II.7, and in direct fluorescence for fluorescein dyes as described in section II.6.

\section{II.4 Experiment outside the International Space Station (ISS)}

Simulating radiation environment in Earth facilities is highly complicated, since it is almost impossible to include all constraints encountered during an entire space mission all together (long duration storage, transportation, take-off/landing shocks, thermal constraints, and cumulative effects of cosmic rays particles). For that purpose, 11 samples ( 7 ground controls, 4 exposed samples also denoted as ISS samples) took part in the ñBiochip in PSS experimentò (Vigier et al., 2013; Cottin et al., 2015) during the EXPOSE-R2 mission. These samples were simultaneously prepared, within the same freeze-drying batch, as that described in the paragraph II.2. The 4 exposed CNES cells were spread on the 2 exposure levels of the Tray 3 of the EXPOSE carrier dedicated to the PSS experiment. Disposition of the 2 CNES cells on the sample carrier were the same for the upper and the lower level of the sample carrier. Launch to ISS (July $\left.23^{\text {th }}, 2014\right)$ and storage inside ISS was at ambient temperature $\left(22-25^{\circ} \mathrm{C}\right.$ on average) (Rabbow et al., 2017). Then, EXPOSE-R2 platform was placed outside the ISS on the Universal platform D on August $18^{\text {th }}$ with opening of the valves on August $20^{\text {th }}$, and removal of the UV shield in October $22^{\text {nd }}, 2014$. On February $3^{\text {rd }} 2016$ trays were covered and brought back inside the ISS. Thus, the exposed samples spent 566 days outside the ISS over the 588 days of the mission (1 year, 8 months). 
Into each CNES cell, two thermoluminescent detectors (TLDs) were placed at the bottom of the cell, below the samples. These passive dosimeters were analyzed at the end of the mission (for detailed methods of analysis see Berger et al.;2012;2015) and revealed that the absorbed

212 dose by our aptamer samples was about $220 \mathrm{mGy}$ for the 588 days of the mission. This absorbed dose is consistent with doses expected for a mission to Mars. Indeed, considering Geant4 simulations in Le Postollec et al. (2009a), this absorbed dose (220mGy) corresponds to 8 months travel and 6 months at Mars surface. Considering doses measured by Curiosity rover (Hassler et al., 2014), this dose corresponds to a mission to Mars with 8 months travel and 18 months at the surface.

During their extravehicular exposition, the samples on Tray 3 were submitted to temperatures varying between $-20.9^{\circ} \mathrm{C}$ and $57.98^{\circ} \mathrm{C}$ (Rabbow et al., 2017). Accurate measurements of the CNES exposed cells temperature were provided by the temperature control interface of the Planetary and Space Simulation Facilities (Microgravity User Support Center (MUSC), http://www.musc.dlr.de/expose-r-2/; Figure 2a). On March $2^{\text {nd }} 2016$, EXPOSE-R2 Tray 3 landed on Earth. During transit from Baikonur cosmodrome to Moscow, and from Moscow to German Aerospace Center (DLR, Germany) a recording of temperatures was done, the temperatures oscillated between $20^{\circ} \mathrm{C}$ and $24^{\circ} \mathrm{C}$. Then from DLR to LISA (Laboratoire Interuniversitaire des Systèmes Atmosphériques, Paris Est-Créteil) (Rabbow et al., 2017), and Paris to Montpellier a controlled chamber at $4{ }^{\circ} \mathrm{C}$ was used during transportation in the summer period. De-integration of the exposed CNES cells from the sample carriers was done according to MUSC/DLR/ESA/CNES internal procedures. On June $24^{\text {th }} 2016$, the soldered joint of all the CNES cells (including ground references) was removed, using a mechanical lathe and a manufactured CNES tool, in the mechanics department of the Montpellier University (Figure 
1c). Samples were immediately sealed in a FoodSaverÊ bag (Fischer Scientific, France) and stored in the dark at $4{ }^{\circ} \mathrm{C}$ until analysis with FP assays.

\section{II.5 EXPOSE-R2 mission ground references}

During the same period, experiments have been performed on ground to control the long-term behaviour of the 49 merYm3 $\tilde{\sigma}$ aptamer upon storage but not exposed to space constraints. Two ground CNES cells were stored at the French Space Agency (CNES, Toulouse) by maintaining an accurate temperature control at $3.9 \pm 0.8^{\circ} \mathrm{C}$ over that period. These samples were named as ñCNES $5^{\circ}$ Cò samples. Three ground CNES cells were kept in DLR (Cologne, Germany): 2 ground CNES cells were stored at $5^{\circ} \mathrm{C}$ (ñDLR $5^{\circ} \mathrm{Cò} \mathrm{samples)} \mathrm{and} 1$ ground CNES cell underwent the same thermal history as ISS samples (ñDLR æTò sample) (see above, Figure 2a). In addition, the behaviour of 2 additional ground samples was studied at DLR combining long time storage, varying thermal environment as ISS ones, and UV radiations (ñDLR æ+UVò samples) (Rabbow et al., 2017). Calibrated Bentham 150 double monochomators instrument equipped with a SOL2000 lamp (Dr. K.Hönle GmbH, Martinsried, Germany) was used to provide a spectrum similar to that of sunlight. All of these 7 ground CNES cells were brought back to Montpellier to be handled simultaneously with the exposed CNES cells during all the desoldering process and $4{ }^{\circ} \mathrm{C}$ storage (section II.4) before running FP assays (section II.7). However, data of DLR æ and DLR æ due to the lack of precision of the applied temperatures.

\section{II.6 Additional ground thermal cycling experiments}

The 49merYm3 $\widehat{\alpha}$ aptamer and fluorescein dye were freeze-dried at $500 \mathrm{nM}$ in ultrapure water as described in section II.2. Thermal cycling experiments were carried out on freeze-dried samples in their sealed bags in a temperature test chamber (Vötsch VT 4004). Two independent 
thermal variation experiments were done: one with a sharp rise in temperature $\left(5^{\circ} \mathrm{C} / \mathrm{min}\right)$ until a one hour plateau at $80^{\circ} \mathrm{C}$ (referred as $\tilde{n} 80^{\circ} \mathrm{C}$ peakò in the text), and a long cycling period (178.8 hours or 7.45 days) mimicking thermal variations of exposed cells (Figure $2 \mathbf{b}$ ) with an amplitude of about $70^{\circ} \mathrm{C}$ (referred as ñong cycleò in the text). After reconstitution of freezedried product with $120 \mu \mathrm{L}$ of deionized water, $100 \mu \mathrm{L}$ were pipetted into black 96-well halfarea microplates from Greiner Bio-One (Courtaboeuf, France) to measure fluorescence intensity of the signal (RFS). Fluorescence measurements were done on a Tecanô Infinite ${ }^{\circledR}$ F500 microplate reader (Mannedorf, Switzerland) having excitation and emission filters at 488 $\mathrm{nm}$ and $525 \mathrm{~nm}$, respectively. A blank signal with neither aptamer nor fluorescein dye was used to evaluate noise value (RFN). Results are presented as signal to noise $(\mathrm{S} / \mathrm{N})$ ratio equals to RFS/ RFN.

\section{II.7 Aptamer-based fluorescence polarization (FP) assay}

For all experiments carried out in ground-based particles accelerator facilities and the overall ISS mission, a structure-switching aptamer assay based on a fluorescence polarization (FP) approach (Figure 3) was used to evaluate the binding ability of the 49 merYm3 $\widehat{\alpha}$ F aptamer towards its $L$-Tym target. The approach, described by Ruta et al. (2009) and Perrier et al. (2010), is based on monitoring the fluorescence anisotropy change (qp) of an aptamer labelled by a single fluorescent dye at its 3ôend. Fluorescence anisotropy change qo was calculated as the difference between the measured anisotropy $(r)$ of the labelled aptamer-target complex, and the anisotropy in absence of target $\left(r_{f}\right)$, which was prepared by replacing the $L$-Tym target solution by deionized water. The optimized binding buffer for FP assay consisted of $10 \mathrm{mM}$ Trisï $\mathrm{HCl}, \mathrm{pH}$ 7.5, $10 \mathrm{mM} \mathrm{MgCl} 2$ and $50 \mathrm{mM} \mathrm{NaCl}$ (Zhu et al., 2011). The aptamer solutions $(500 \mathrm{nM})$ were heated at $80^{\circ} \mathrm{C}$ for $5 \mathrm{~min}$ for denaturation then left to stand at room temperature in the dark for 30min. $100 \mu \mathrm{L}$ of the renatured aptamer solutions were deposited into black 96- 
well half-area microplates containing the increasing concentrations of $L$-Tym $(0.5 / 1 / 2.5 / 5 / 7.5 / 10$ or $12.5 / 25.0 / 40.0$ or $50.0 / 80.0 / 200.0 \mu \mathrm{M})$ for measurements on Tecan's Infinite ${ }^{\circledR}$ M1000 PRO (Tecan, France). Excitation was set at $485 \pm 20 \mathrm{~nm}$, and emission was collected with $535 \pm 25 \mathrm{~nm}$ bandpass filters.

\section{II.8. Data interpretation and statistical analysis}

For a 1:1 stoichiometry, the measured anisotropy $(r)$ can be linked to the apparent dissociation constant $K_{d}$ via the following relation:

$$
r=\frac{r_{f} K_{d}+r_{b} c}{K_{d}+c}
$$

where $r_{f}$ is the anisotropy in the absence of target, $r_{b}$ the anisotropy of maximally targetassociated aptamer, and $c$ the concentration of free target. For a limiting aptamer probe concentration, the total concentration of $\operatorname{target}\left(c_{T}\right)$ in the reaction system approximates the free target concentration $c$. The nonlinear regression of the $r$ versus $c\left(\stackrel{\circ}{c_{T}}\right)$ plots, where $r_{b}$ and $K_{d}$ constituted the adjustable parameters, was achieved using the Table curve 2D software (Systat Software Gmbh, Erkrath, Germany).

To evaluate cosmic rays effects on freeze-dried exposed aptamers, control samples were prepared with an aptamer probe that did not undergo freeze-drying process or irradiation (reference sample). Binding affinity data for exposed samples and control samples were compared using the relative dissociation constant value (relative $K_{d}$ ) expressed as follow:

$$
\frac{K_{d \text { (irradiated })}}{K_{d(\text { control })}}
$$

\section{Relative $K_{d}$ values are reported in Table 2.}

For the ISS experiments, relative $K_{d}$ were estimated from freeze-dried ground samples stored at $5^{\circ} \mathrm{C}$ in DLR facility during all the duration of the mission. ñFlight samplesòcorresponded 
to ISS samples that undergo all cumulative effects of the mission (flights, extravehicular exposure, and transportation). Relative $K_{d}$ values are reported in Table 3. All data are reported as the mean \pm the standard deviation (SD) from at least four replicate experiments. Statistical significance of the assays was determined using Studentô $t$-test $(p=0.05)$. 
We first determined a reference value of the affinity of the aptamer used to its target. In the various FP assays we performed, the concentration of 49merYm3 $\tilde{\mathrm{f}}$ aptamer was constant $(500 \mathrm{nM})$ and its target $L$-Tym increased in concentrations from 0.5 to $200 \mu \mathrm{M}$ (10 levels of concentrations, see experimental part). Binding data of 49 merYm3 $\hat{\mathrm{f}}$ aptamer to $L$-Tym were globally fit to four parameter logistic regressions permitting the calculation of $K_{d}$ $(1.54 \pm 0.14 \mu \mathrm{M}$, aptamer batches $1,2,3, \mathrm{n}=14)$, which is comparable with previous published data (Ruta et al., 2009).

\section{III.1. Irradiation effects on aptamers during ground-based experiments}

To minimize experimental error, all assays were performed at least in triplicate. Affinity curves do not reveal significant differences in anisotropy change op- (Figure 4). The corresponding relative $K_{d}$ values were calculated (Eq. 2), and reported in Table 2. The aim of the present study, according to the particle types, fluences, energies and exposure durations, is to determine whether irradiated samples undergo damaging effects on the (statistically identical $K_{d}$ values), differences in $æ$ were observed with other particles. For instance, in Figure 4b, a slight difference was observed in between the two irradiated samples with electrons. However, analysis of the relative $K_{d}$ for both irradiated samples shows that there were statistically identical $(p>0.05)$ compared to the corresponding reference. This suggests that the recognition capabilities of the 49 merYm $3 \hat{\sigma}$ F aptamer were not affected by the irradiation process even when using higher fluence and irradiation duration. The same phenomenon was observed with neutrons: the higher fluence $\mathrm{F}_{\mathrm{n} 1}$ induced 
a larger decrease in anisotropy change $\mathbf{q p}$ (Figure $\mathbf{4 c}$ ). The relative $K_{d}$ value corresponding to irradiated sample with $\left(\mathrm{F}_{\mathrm{n} 1} ; \mathrm{E}_{\mathrm{n}} ; \mathrm{D}_{\mathrm{n} 1}\right)$ radiation conditions (which presents higher variability), stayed statistically identical to the reference one. Consequently, we hypothesized that high fluences of electrons and neutrons might have deleterious effects on the fluorescein dye. To verify that point, we run a Student's $t$-test on fluorescence intensities obtained for fluorescein dye before and after irradiations. It revealed that significant differences could be observed with up to $40 \%$ loss in fluorescence signal for high fluence $F_{n 1}$ for neutrons and fluence $F_{p 1}$ at both energies $E_{p 1}$ and $E_{p 2}$ for protons. So, potential degradation of fluorescein dye might occur with higher fluence. Thus, after exposure to $\left(\mathrm{F}_{\mathrm{e} 1}\right.$; $\left.\mathrm{E}_{\mathrm{e}} ; \mathrm{D}_{\mathrm{e} 1}\right)$ radiation with electrons beam and $\left(\mathrm{F}_{\mathrm{p} 1} ; \mathrm{E}_{\mathrm{p} 1}\right)$ et $\left(\mathrm{F}_{\mathrm{p} 1} ; \mathrm{E}_{\mathrm{p} 2}\right)$ radiation with protons beam, fluorescence anisotropy changes might not be due to alteration of binding but rather suggest some alterations of the fluorescein dye emitting properties. In addition, with protons, cumulative effects were observed. Indeed, the results of FP measurements after protons irradiation showed a small discrepancy between the reference sample and the 4 irradiated ones (Figure 4d). Although $K_{d}$ values were slightly smaller than that of the reference (Table 2), they remained statistically identical. All radiation configurations tested led to a similar anisotropy change $q p$ that could suggest there was no important damage in the structure of the 49 merYm3 $\tilde{F}$ aptamer that consequently could alter the binding to its target $L$-Tym. Compared to our previous published data (Baqué et al., 2011b), showing that $2 \mathrm{MeV}$ protons had no effect on the binding affinity of irradiated 49merYm3 $\hat{\sigma} F$ aptamer neither on the fluorescein dye, the present data might suggest that higher energies of protons (25 MeV/50 353 $\mathrm{MeV}$ ) alter the fluorophore. 
Since radiation gradients were observed on the EXPOSE platform in previous ISS missions (Berger et al., 2012; 2015), the 4 exposed aptamers ñFlight samplesò were spread on the 2 exposure levels of the Tray 3 of the EXPOSE carrier dedicated to the PSS experiment, but with the same disposition on the upper and lower level of the sample carrier. However, measurements performed with passive dosimeters during the EXPOSE-R2 mission revealed, a posteriori, that the absorbed dose difference between cells at upper and lower levels was extremely low (about $3 \mathrm{mGy}$ for the whole mission corresponding to $1.4 \%$ of the total). Some TLDs stacks composed of eleven TLDs included into Tray 3 structure bring explanations on this very low difference. As can be seen in Figure 5, absorbed dose decreases when shielding increases but after $\sim 0.75 \mathrm{~g} / \mathrm{cm}^{2}$ of shielding, the absorbed dose measured remains quasi stable and the dose decrease evolves very slowly even if shielding is significantly increased. As the estimated shielding of TLDs placed into cells on the upper level is about $0.82 \mathrm{~g} / \mathrm{cm}^{2}$, it explains the very low absorbed dose difference observed between both levels.

Calculation of $K_{d}$ from independently and freshly prepared reference samples was $1.58 \pm 0.12$ $\mu \mathrm{M}$ (aptamer batch 4), which is comparable with the above reference value $(1.54 \pm 0.14)$. However, $K_{d}$ values from the 8 mission samples appeared to be on average 1.5-2 times higher. We previously verified that freeze-drying induced no effects on binding curves nor in $K_{d}$ value. However, storage stability analyses of freeze-dried 49merYm3 $\hat{F}$ aptamer (batches $1 \& 2$ ), carried out at $4{ }^{\circ} \mathrm{C}$ for 20 days and 7 months, showed differences in anisotropy change op for the different storage times and aptamer batches (data not shown). Consequently, to only take into account the effects encountered during the ISS mission (flights, extravehicular exposure, and all transportations during the mission) relative $K_{d}$ were calculated using the freeze-dried ground samples stored at $5^{\circ} \mathrm{C}$ in DLR facility during all the duration of the mission. The binding 
curves and the corresponding relative $K_{d}$ values are reported in Figure 6 and Table 3, respectively. We distinguished two groups of affinity curves. Group1 concerns the highest measured anisotropy change op with both ground controls stored at $5^{\circ} \mathrm{C}$ (DLR and CNES) during the mission. Group 2 represents the flight samples. We note that the ñower trayòsamples seem to have a different behaviour than the flight samples exposed in the ñupper trayò.

Based on these observations, an effect due to the temperature variations during the mission can be invoked. To test this hypothesis, post-flight ground thermal cycling experiments were carried out on the 49 merYm3 $\hat{\alpha}$ aptamer and the fluorescein dye over a $80^{\circ} \mathrm{C}$ short peak of temperature and a long cycle mimicking thermal variations of flight samples (see section II.6 of the experimental part and Figure 2b). S/Ref values were 74.5 $\pm 15.1,62.1 \pm 23.5$, and 59.0 \pm 14.9 for the freeze-dried fluorescein reference, the $80^{\circ} \mathrm{C}$ peak, and long cycle, respectively. The aptamer S/Ref values were $23.3 \pm 5.9,23.5 \pm 10.4$, and $70.6 \pm 20.8$ for the reference, the $80^{\circ} \mathrm{C}$ peak, and long cycle, respectively. Consequently, there is no great impact of thermal variation upon the fluorescence properties of the freeze-dried dye. On the contrary, significant differences were observed with the 49 merYm3 $\hat{\alpha} F$ aptamer, with the same order of S/Ref for the long cycle (70.6 \pm 20.8$)$ as for the reference of the free dye $(74.5 \pm 15.1)$. These both values are statistically identical $(p>0.05)$. One possible explanation could be that a long cycle affected the photochemical features of the fluorescein dye when attached to aptamer and consequently induced both a decrease in the fluorescence anisotropy and a higher variability in all signals (Perrier $e t$ al., 2009). Dye played a preponderant role in the performance of the FP assays (Perrier et al., 2018).

$K_{d}$ values of flight ñupper \& lower trayò samples are not statistically different from ground ñDLR $5^{\circ} \mathrm{Cò}$ and ñCNES $5^{\circ} \mathrm{Cò} \mathrm{controls.} \mathrm{Consequently,} \mathrm{based} \mathrm{on} \mathrm{the} \mathrm{above} \mathrm{considerations,} \mathrm{our}$ 
403 results showed that aptamer recognition capabilities were not affected during the overall flight

404 mission or that the degradations are too small to be detected by our analysis protocol. 
During the last years, we used various facilities producing protons, electrons, neutrons and 407 heavy ions to test whether cosmic particles could induce changes in aptamer binding events. However, simulating space radiation environment in Earth facilities remains impossible due to the great number of variables. So, we also carried out a real space exposure of aptamer samples outside the ISS during the EXPOSE-R2 mission.

The results presented in this paper suggest that cosmic radiation has no significant effect on the aptamers recognition ability. On the contrary, repeated temperature cycling seems to alter the mobility of its fluorescein dye. This effect results in a lowering of the recognition step signal that could be interpreted as a loss of recognition, or as the absence of the target, or as an alteration of the fluorescent dye properties. In all cases, it alters the limit of detection of the biochip.

In our context, since we controlled the concentration of the target and we obtained $K_{d}$ values similar to the reference value, we attribute the lowering of signal as a modification of fluorescent dye mobility. So, we suggest conducting further studies to improve the detection step using another fluorescent dye or another detection method.

\section{Acknowledgments}

The authors would like to thank the French national space agency (CNES) for financial support (05/2182/00-DCT094). The authors also thank all staff from the Louvain-la-Neuve cyclotron facility, from the Bergonié Institut, and the staff from the Istituto Nazionale di Fisica Nucleare of Catania for their assistance during irradiation experiments. The authors thank Jean-Louis 
428 during the desoldering of the CNES cells, and Dr. Sonia Khier for her assistance that has led to

429 good progress during the analysis of samples.

430 


\section{References}

Baqué, M., Le Postollec, A., Coussot, G., Moreau, T., Desvignes, I., Incerti, S., Moretto, P., Dobrijevic, M., Vandenabeele-Trambouze, O. (2011a) Biochip for astrobiological applications: Investigation of low energy protons effects on antibody performances. Planetary and Space Science 59(13):1490 ї 1497.

Baqué, M., Le Postollec, A., Ravelet, C., Peyrin, E., Coussot, G., Desvignes, I., Incerti, S., Moretto, P., Dobrijevic, M., Vandenabeele-Trambouze, O. (2011b) Investigation of LowEnergy Proton Effects on Aptamer Performance for Astrobiological Applications. Astrobiology 11(3): 207ï 211.

Baqué, M., Dobrijevic, M., Le Postollec, A., Moreau, T., Faye, C., Vigier, F., Incerti, S., Coussot, G., Caron, J., Vandenabeele-Trambouze, O. (2017) Irradiation effects on antibody performance in the frame of biochip-based instruments development for space exploration. International Journal of Astrobiology 16(1): 82-90.

Berger, T., Hajek, M., Bilski, P., Koerner, C., Vanhavere, F., Reitz, G. (2012). Cosmic radiation exposure of biological test systems during the EXPOSE-E mission. Astrobiology 12(5): $387 і ̈ 392$.

Berger, T., Hajek, M., Bilski, P., Reitz, G. (2015). Cosmic radiation exposure of biological test systems during the EXPOSE-R mission. International Journal of Astrobiology, 14(1), 2732

Cottin, H., Saiagh, K., Nguyen, D., Grand, N., Benilan, Y., Cloix, M., Coll, P., Gazeau, M-C., Fray, N., Khalaf, D., Raulin, F., Stalport, F., Carrasco, N., Szopa, C., Chaput, D., Bertrand, M., Westall, F., Mattioda, A., Quinn, R., Ricco, A., Santos, O., Baratta, G., Strazzulla, G., Palumbo, M.E., Le Postollec, A., Dobrijevic, M., Coussot, G., Vigier, F., VandenabeeleTrambouze, O., Incerti, S., Berger, T. (2015) Photochemical studies in low Earth orbit for organic compounds related to small bodies, Titan and Mars. Current and future facilities, Bulletin de la Société Royale des Sciences de Liège 84 : 60-73.

Cottin, H., Kotler, J.M., Billi, D., Cockell, C., Demets, R., Ehrenfreund, P., Elsaesser, A., dốHendecourt, L., van Loon, J.J.W.A., Martins, Z., Onofri, S., Quinn, R.C., Rabbow, E., Rettberg, P., Ricco, A.J., Slenzka, K., de la Torre, R., de Vera, J.-P., Westall, F., Carrasco, N., Fresneau, A., Kawaguchi, Y., Kebukawa, Y., Nguyen, D., Poch, O., Saiagh, K., Stalport, F., Yamagishi, A., Yano, H. and Klamm, B.A. (2017) Space as a Tool for Astrobiology: Review and Recommendations for Experimentations in Earth Orbit and Beyond. Space Science Reviews 209, 83-181.

Coussot, G., Moreau, T., Faye, C., Vigier, F., Baqué, M., Le Postollec, A., Incerti, S., Dobrijevic, M., Vandenabeele-Trambouze, O. (2017) Biochip-based instruments development 
for space exploration: influence of the antibody immobilization process on the biochip resistance to freeze-drying, temperature shifts and cosmic radiations. International Journal of Astrobiology 16(2):190-199.

Coussot, G., Faye, C., Le Postollec, A., Dobrijevic, M. (2018a) A methodological approach for the thermal stability and stress exposure studies of a model antibody. Analytical Biochemistry, 548: 23-31.

Coussot G., Le Postollec A., Faye C., Baqué M., Vandenabeele-Trambouze O., Incerti S., Vigier F., Chaput D., Cottin H., Przybyla B., Berger T., Dobrijevic M. (2018b) Photochemistry on the Space Station - Antibody resistance to space conditions after exposure outside the International Space Station. Astrobiology, in press.

de Diego-Castilla, G., Cruz-Gil, P., Mateo-Martí, E., Fernández-Calvo, P., Rivas, L.A., Parro, V. (2011) Assessing antibody microarrays for space missions: effect of long-term storage, gamma radiation, and temperature shifts on printed and fluorescently labeled antibodies. Astrobiology 11(8):759ï 773.

Derveni, M., Allen, M., Sawakuchi, G.O., Yukihara, E.G., Richter, L., Sims, M.R., Cullen, D.C. (2013) Survivability of immunoassay reagents exposed to the space radiation environment on board the ESA BIOPAN-6 Platform as a prelude to performing immunoassays on Mars. Astrobiology 13(1):93-102.

Derveni, M., Hands, A., Allen, M., Sims, M.R., \& Cullen, D.C. (2012) Effects of simulated space radiation on immunoassay components for Life-detection experiments in planetary exploration missions. Astrobiology 12(8): 718 ï 729.

Dong, Y., Xu, Y., Yong, W., Chu, X., Wang, D. (2014) Aptamer and its potential applications for food safety. Critical Reviews in Food Science and Nutrition. 54(12): 1548-1561.

Gotrik, M.R., Feagin, T.A., Csordas, A.T., Nakamoto, M.A., Soh, H.T (2016) Analysis of aptamer discovery and technology. Accounts of chemical research 49(9):1903-1910.

Hassler, D M., Zeitlin, C., Wimmer-Schweingruber, R F.; Ehresmann, B.; Rafkin, S.; Eigenbrode, J L.; Brinza, D E.; Weigle, G.; Böttcher, S.; Böhm, E.; and 438 coauthors (2014) Mars' Surface Radiation Environment Measured with the Mars Science Laboratory's Curiosity Rover. Science 343 (6169), id. 1244797.

Le Postollec, A. , Dobrijevic, M., Incerti, S., Moretto, P., Seznec, H., Desorgher, L., Santin, G., Nieminen, P., Dartnell, L., Vandenabeele-Trambouze, O., Coussot, G. (2007)

Development of a Biochip dedicated to planetary exploration. First step: resistance studies to space conditions. Journées Semaine de lôAstrophysique Française 2007. 
Le Postollec, A., Incerti, S., Dobrijevic, M., Desorgher, L., Santin, G., Moretto, P., Vandenabeele-Trambouze, O., Coussot, G., Dartnell, L., Nieminen, P. (2009a) Monte Carlo simulation of the radiation environment encountered by a biochip during a space mission to Mars. Astrobiology 9(3): 311 ï 323.

Le Postollec, A., Coussot, G., Baqué, M., Incerti, S., Desvignes, I., Moretto, P., Dobrijevic, M., Vandenabeele-Trambouze, O. (2009b) Investigation of Neutron Radiation Effects on Polyclonal Antibodies (IgG) and Fluorescein Dye for Astrobiological Applications. Astrobiology 9(7): 637ї 645.

Martins, Z. (2011) In situ biomarkers and the Life Marker Chip. Astronomy \& Geophysics $52(1): 1.34-1.35$.

McKay, C.P.,Stoker, C.R., Glass, B.J., Davé, A., Davila, A.F., Heldmann, J.L., Marinova, M.M., Fairen, A.G., Quinn, R.C., Zacny, K.A., Paulsen, G., Smith, P.H., Parro, V., Andersen, D.T., Hecht, M.H., Lacelle, D., Pollard, W.H. (2013) The Icebreaker Life Mission to Mars: A Search for Biomolecular Evidence for Life. Astrobiology 13(4): 334 ï 353.

McKenna-Lawlor, S., Gonçalves, P., Keating, A., Reitz, G., Matthiä, D. (2012) Overview of energetic particle hazards during prospective manned missions to Mars. Planetary and Space Science 63ї 64(0): $123 \ddot{1} 132$.

Parro, V., Rodriguez-Manfredi, J.A., Briones, C., Compostizo, C., Herrero, P.L., Vezb, E., Sebastián, E., Moreno-Paz, M., García-Villadangos, M., Fernández-Calvo, P., González-Toril, E., Pérez-Mercader, J., Fernández-Remolar, D., Gómez-Elvira, J. (2005) Instrument development to search for biomarkers on mars: Terrestrial acidophile, iron-powered chemolithoautotrophic communities as model systems. Planetary and Space Science 53(7):729-737.

Parro, V., Fernández-Remolar, D., Rodríguez-Manfredi, J.A., Cruz-Gil, P., Gómez-Elvira, J. (2008) SOLID2: an antibody array-based Life-detector instrument in a Mars drilling simulation experiment (MARTE). Astrobiology 8(5): $987 і ̈ 999$.

Parro, V., Fernández-Remolar, D., Rodríguez-Manfredi, J.A., Cruz-Gil, P., Rivas, L.A., RuizBermejo, M., Moreno-Paz, M., García-Villadangos, M., Gómez-Ortiz, D., Blanco-López, Y., Menor-Salván, C., Prieto-Ballesteros, O., Gómez-Elvira, J. (2011a) Classification of modern and Old Rio Tinto sedimentary deposits through the biomolecular record using a Life Marker Biochip: Implications for detecting life on Mars. Astrobiology 11(1): 29 ï 44.

Parro, V., de Diego-Castilla, G., Rodríguez-Manfredi, J.A. , Rivas, L.A., Blanco-López, Y., Sebastián, E., Romeral, J., Compostizo, C., Herrero, P.L., García-Marín, A., Moreno-Paz, M., García-Villadangos, M., Cruz-Gil, P., Peinado, V., Martín-Soler, J., Pérez-Mercader, J., 
Gómez-Elvira, J. (2011b) SOLID3: a multiplex antibody microarray-based optical sensor instrument for in situ Life detection in planetary exploration. Astrobiology 11(1): 15 ï 28.

Perrier, S., Ravelet, C., Guieu, V., Roy, B., Perigaud, C., Peyrin, E. (2010) Rationally designed aptamer-based fluorescence polarization sensor dedicated to the small target analysis. Biosensors \& Bioelectronics 25:1652ï 1657.

Perrier, S., Guieu, V., Chovelon, B., Ravelet, C., Peyrin, E. (2018) Panoply of fluorescence polarization/anisotropy signaling mechanisms for functional nucleic acid-based sensing platforms. Analytical Chemistry 90: 4236-4248.

Rabbow, E., Rettberg, P., Parpart, A., Panitz, C., Schulte, W., Molter, F., Willnecker, R. (2017). EXPOSE-R2: The Astrobiological ESA Mission on Board of the International Space Station. Frontiers in Microbiology, 8, 1533. http://doi.org/10.3389/fmicb.2017.01533.

Rozenblum, G.T., Lopez, V.G., Vitullo, A.D., Radrizzani, M. (2016) Aptamers: current challenges and future prospects. Expert Opinion on Drug Discovery 11(2): 127-135.

Ruta, J., Perrier, S., Ravelet, C., Fize, J., Peyrin, E. (2009) Noncompetitive fluorescence polarization aptamer-based assay for small molecule detection. Analytical Chemistry 81:7468ї 7473.

Sims, M.R., Pullan, D., Holt, J., Blake, O., Sykes, J., Samara-Ratna, P., Canali, M., Cullen, D.C., Rix, C.S., Buckley, A., Derveni, M., Evans, D., Miguel García-Con, L., Rhodes, A., Rato, C.C., Stefinovic, M., Sephton, M.A., Court, R.W., Bulloch, C., Kitchingman, I., Ali, Z., Borst, G., Leeuwis, H., Prak, A., Norfini, A., Geraci, E., Tavanti, M., Brucato, J., Holm, N. (2012) Development status of the life marker chip instrument for ExoMars. Planetary and Space Science 72(1): 129 ï 137.

Smith, H., Parro, V. (2014) Planetary Protection Plan for an Antibody based instrument proposed for Mars2020. in 40 $0^{\text {th }}$ COSPAR Scientific Assembly. p. 3140.

Song, K-M., Lee, S., Ban, C. (2012) Aptamers and Their Biological Applications, Sensors (Basel) 12(1): 612ї 631.

Vigier, F., Le Postollec, A., Coussot, G., Chaput, D., Cottin, H., Berger, T., Triqueneaux, S., Dobrijevic, M., Vandenabeele-Trambouze, O. (2013) Preparation of the Biochip experiment on the EXPOSE-R2 mission outside the International Space Station. Advances in Space Research 52(12): $2168 і ̈ 2179$.

Zhu, Z., Schmidt, T., Mahrous, M., Guieu, V., Perrier, S., Ravelet, C., Peyrin, E. (2011) Optimization of the structure-switching aptamer-based fluorescence polarization assay for the sensitive tyrosinamide sensing. Analytica Chimica Acta 707: 191-196. 


\section{Figures}

\section{Figure 1}

1a)

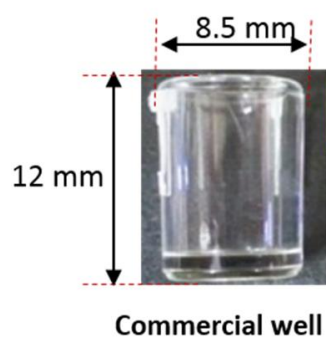

1b)
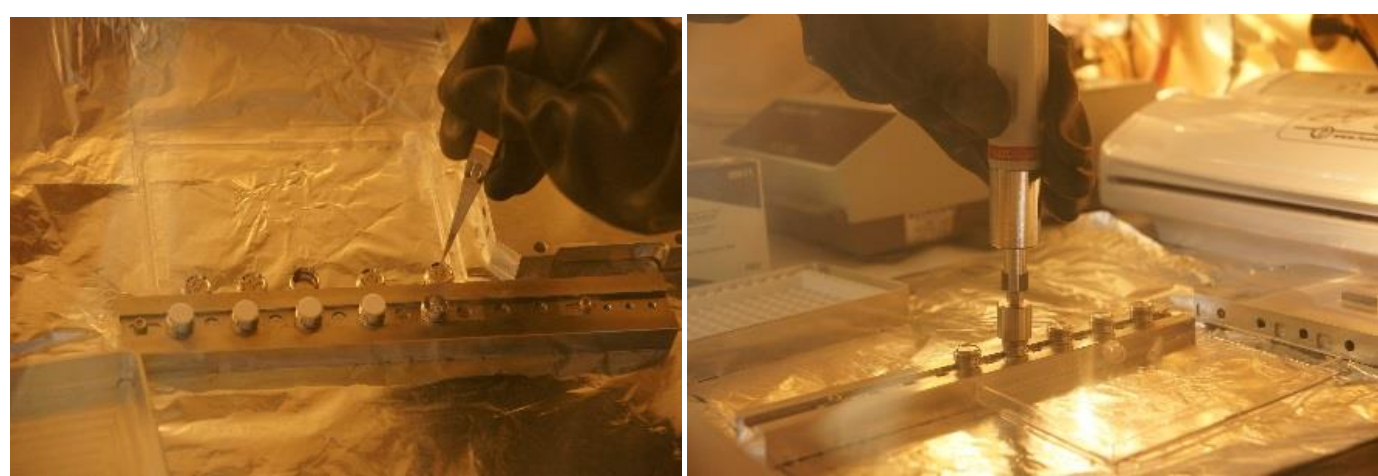

1c)
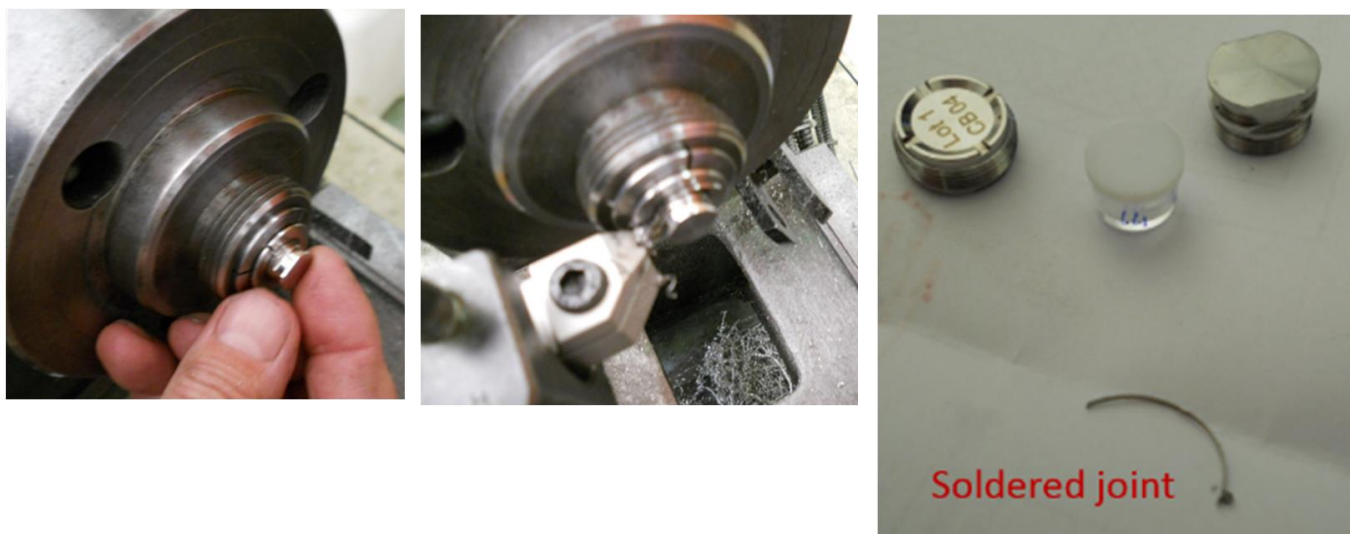

Figure 1 caption:

1a) Design and dimension of the home-designed well and its cap.

1b) Incorporation of capped well into CNES cells under controlled atmosphere and final screwing of closed CNES cells using a torque screwdriver.

1c) Post-flight opening of the CNES cells to remove the soldered joint. 
Figure 2

2a)

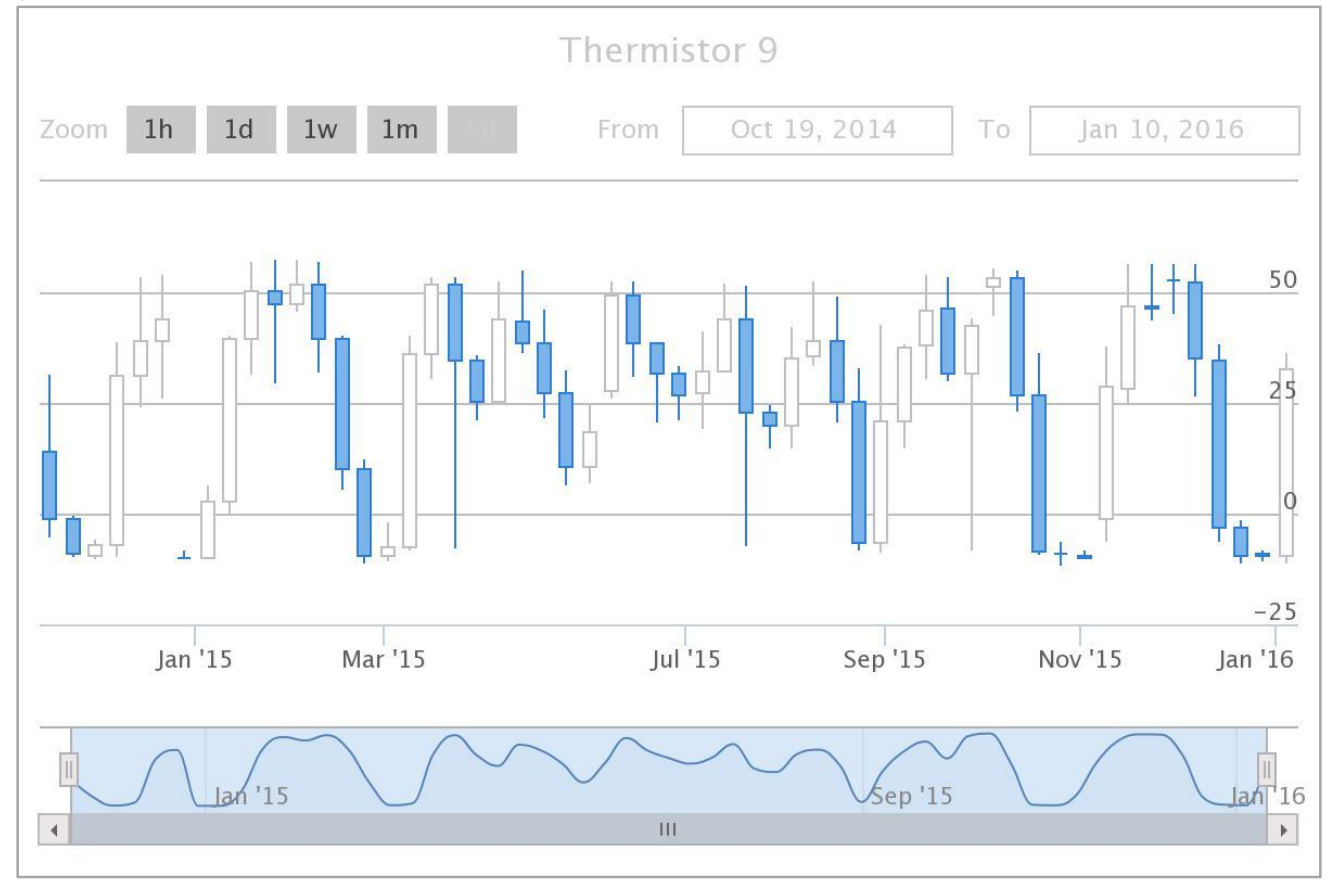

2b)

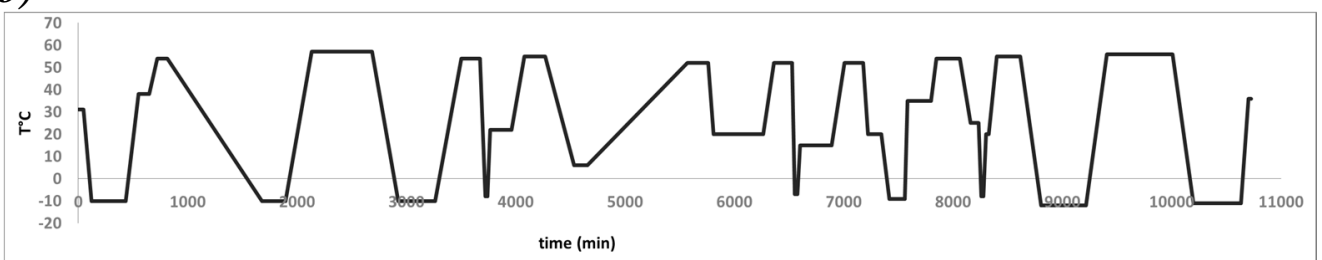

Figure 2 caption:

2a) Overview of the EXPOSE-R2 temperature profiles for tray 3 on thermistor 9 sensor during the EXPOSE-R2 mission (from October 19, 2014 to January 10, 2016, http://www.musc.dlr.de/expose-r-2/).

2b) Ground thermal cycling experiments mimicking thermal CNES cells exposure outside the ISS but in accelerated time: one hour of EXPOSE-R2 mission was converted into one minute to carry out this experiment in lab, and temperature amplitude was similar (referred as long cycle in the text). 
Figure 3

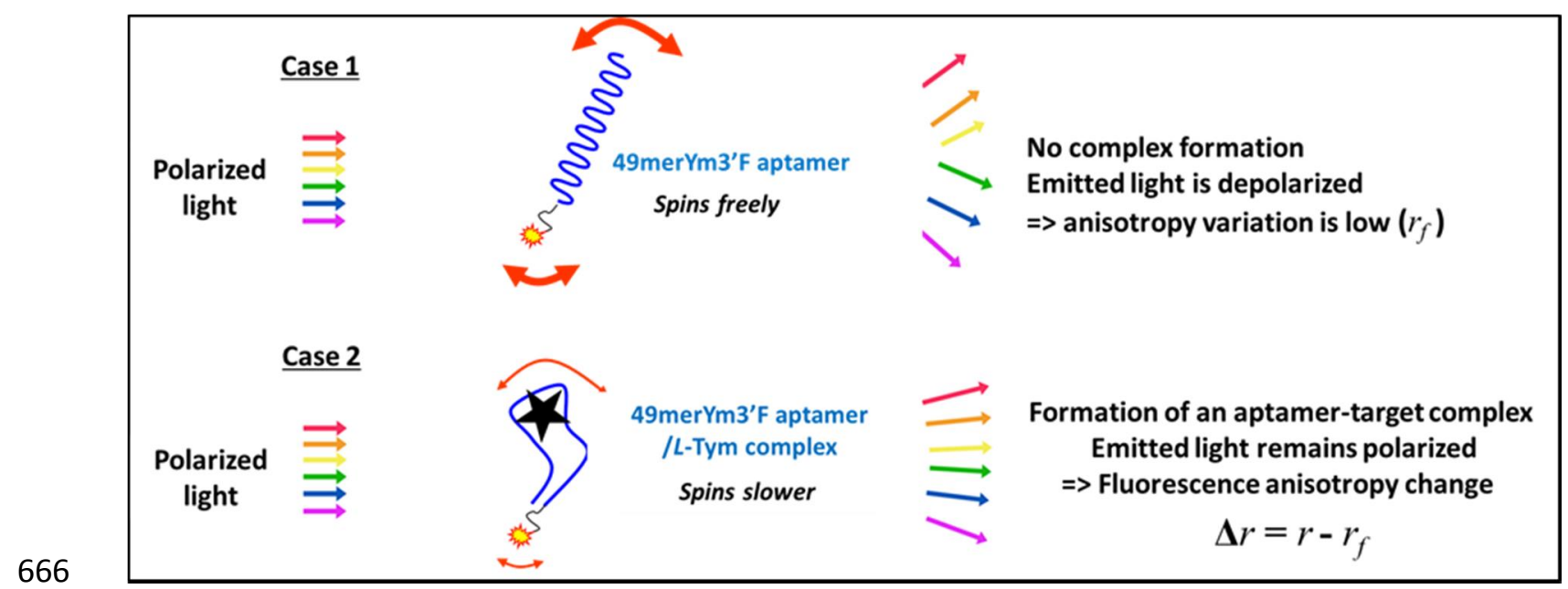

668 Figure 3 caption: Principle of the fluorescence polarization (FP) assays. A fluorescence 669 anisotropy increase is observed upon the formation of a labelled aptamer-target complex. 
670

671

672

673

674

675

676

677

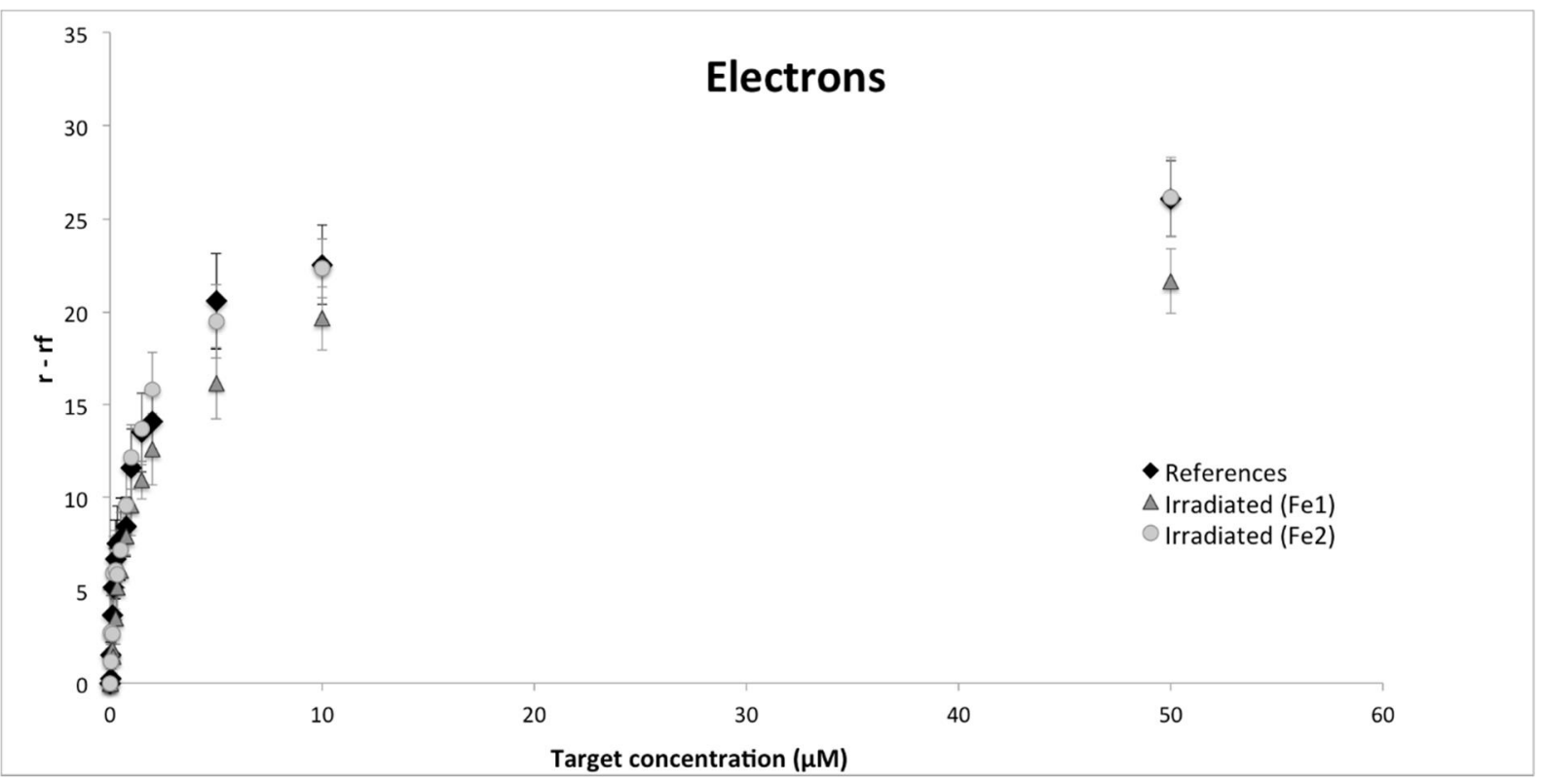




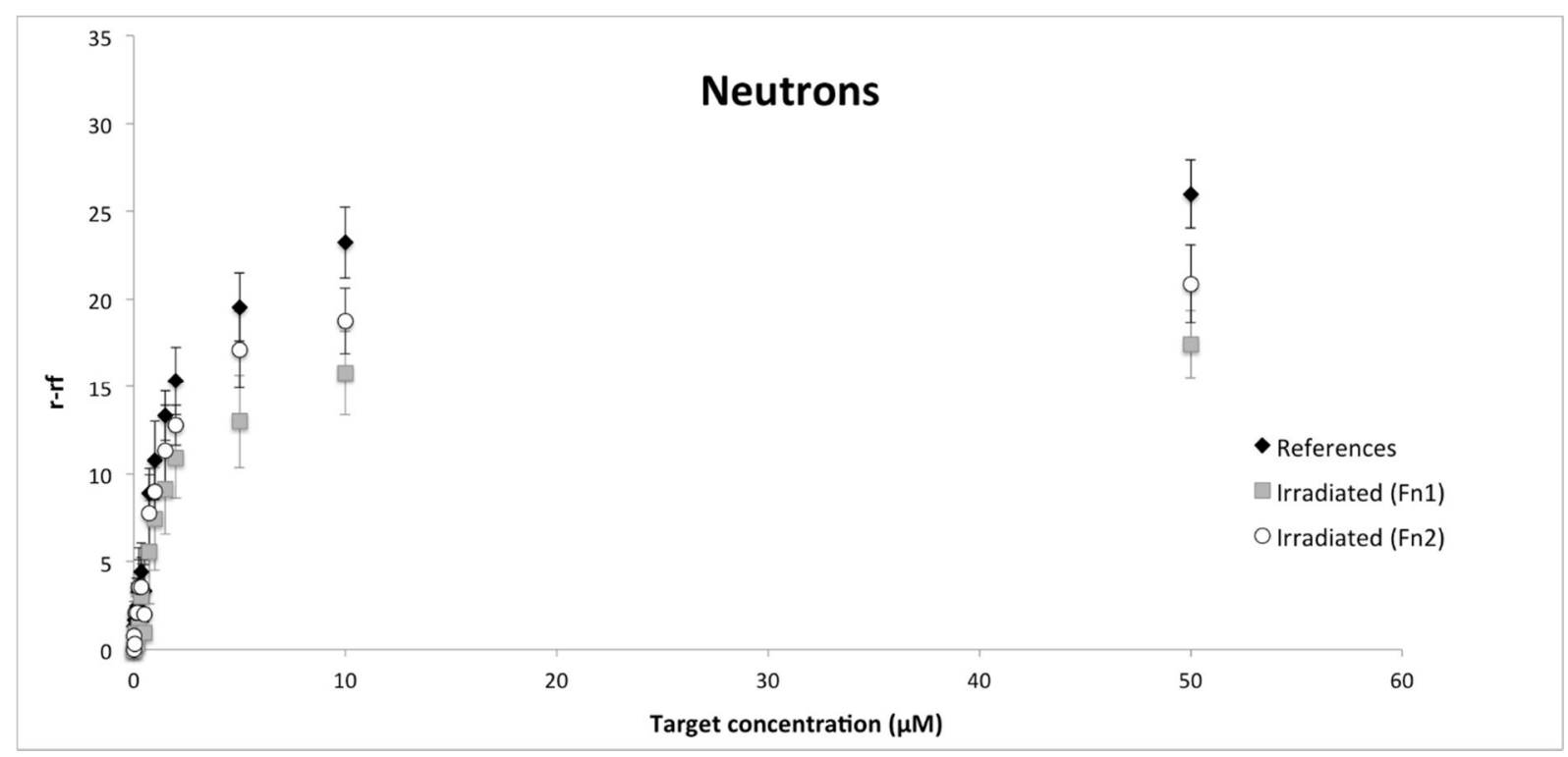

684

685 4d)

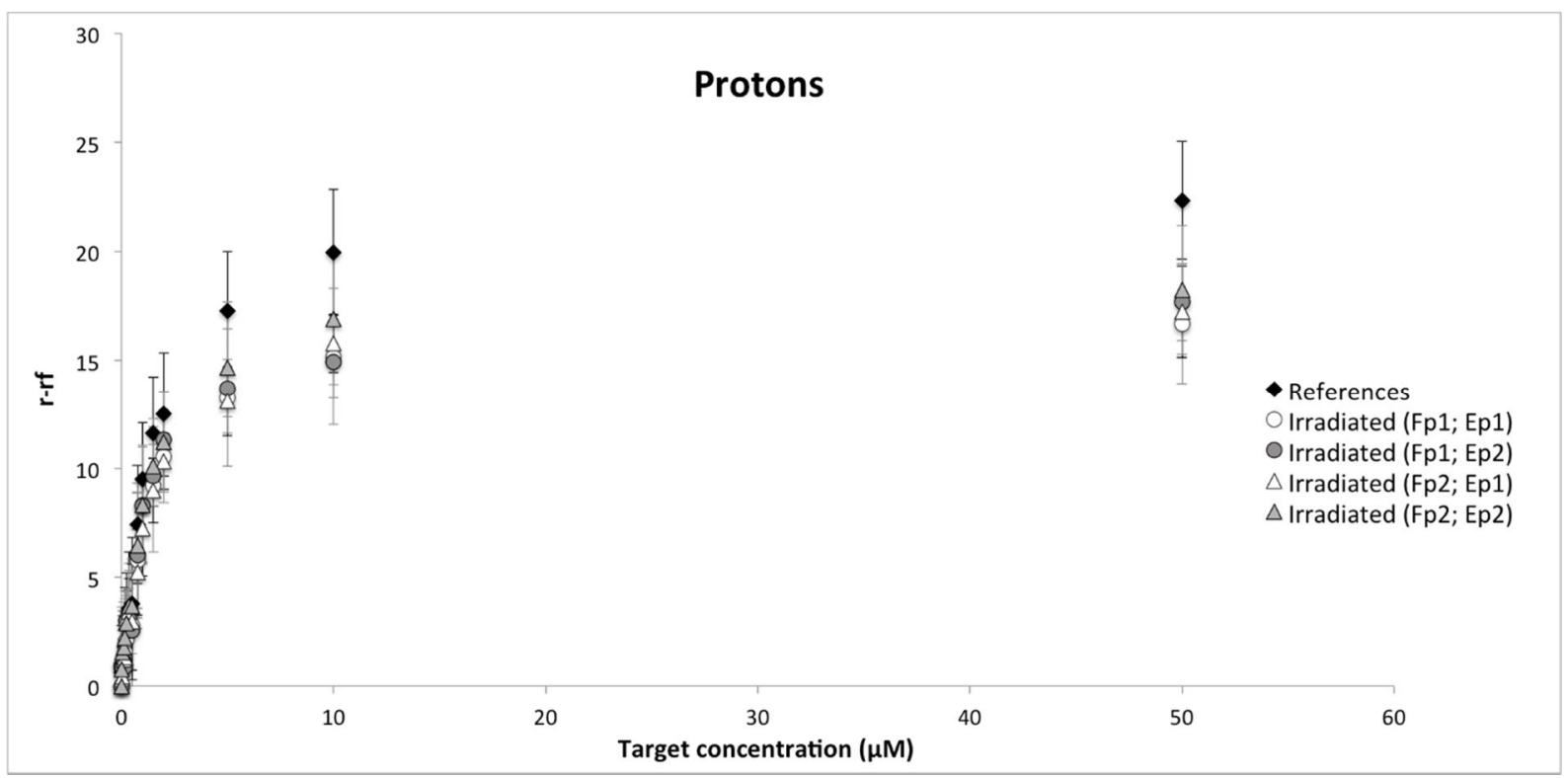

687 Figure 4 caption: Affinity curves for 49 merYm3 $\tilde{\alpha}$ aptamer with additions of $L$-Tym

688 obtained for reference (non irradiated sample), and irradiated samples with particles at various 689 fluence (F), energy (E), and irradiation duration (D), (for details see Table 1). The saturation 690 curves were used for the determination of dissociation constant values (Kd) (Eq. 2) by non691 linear regression analysis. The calculated relative $\mathrm{Kd}$ are listed in Table 2. Reference samples $692(\mathrm{n}=3$ or 6$)$ are labelled in black diamond. 
4a) Irradiated samples with $12 \mathrm{C}$ ions $(\mathrm{Fc}$; $\mathrm{Ec}$; Dc) are illustrated in grey cycle $(\mathrm{n}=3) .4 \mathrm{~b})$ Irradiated samples are represented in dark grey triangle with electron fluences of 3.1011 $\mathrm{p} / \mathrm{cm} 2(\mathrm{Fe} 1 ; \mathrm{n}=4)$ and with a grey circle for $3.1010 \mathrm{p} / \mathrm{cm} 2$ fluence $(\mathrm{Fe} 2 ; \mathrm{n}=4)$.

4c) Irradiated samples with neutron fluences of $3.1013 \mathrm{p} / \mathrm{cm} 2(\mathrm{Fn} 1 ; \mathrm{n}=3)$ are illustrated in grey square, and $3.1012 \mathrm{p} / \mathrm{cm} 2(\mathrm{Fn} 2 ; \mathrm{n}=3)$ in empty circle.

4d) Irradiated sample with protons fluence of $3.1012 \mathrm{p} / \mathrm{cm} 2$ with energy of $25 \mathrm{MeV}$ (Fp1; $\mathrm{Ep} 1 ; \mathrm{n}=3$ ) are represented in empty circle, and in grey circles for an energy of $50 \mathrm{MeV}$ (Fp1; $\mathrm{Ep} 2 ; \mathrm{n}=3)$. Fluence of $3.1011 \mathrm{p} / \mathrm{cm} 2$ with energy of $25 \mathrm{MeV}(\mathrm{Fp} 2 ; \mathrm{Ep} 1 ; \mathrm{n}=3)$ are plotted with an empty triangle, and with an energy of $50 \mathrm{MeV}(\mathrm{Fp} 2 ; \mathrm{Ep} 2 ; \mathrm{n}=3)$ with a grey triangle. 
Figure 5

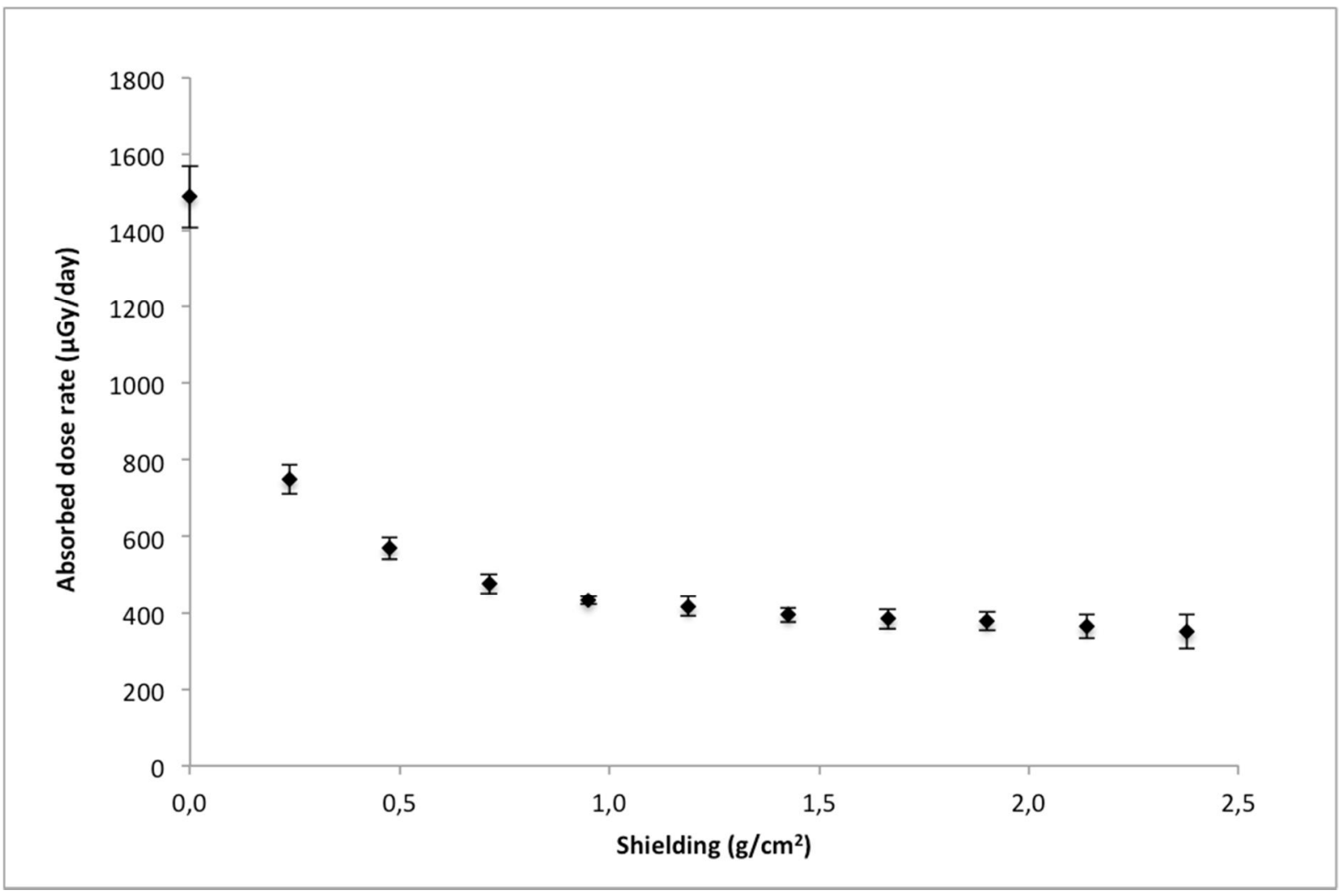

Figure 5 caption: Evolution of the absorbed dose rate as a function of the shielding. Measurements were performed on 5 stacks of 11 TLDs placed into the Tray 3 during EXPOSE-R2 mission.

710 


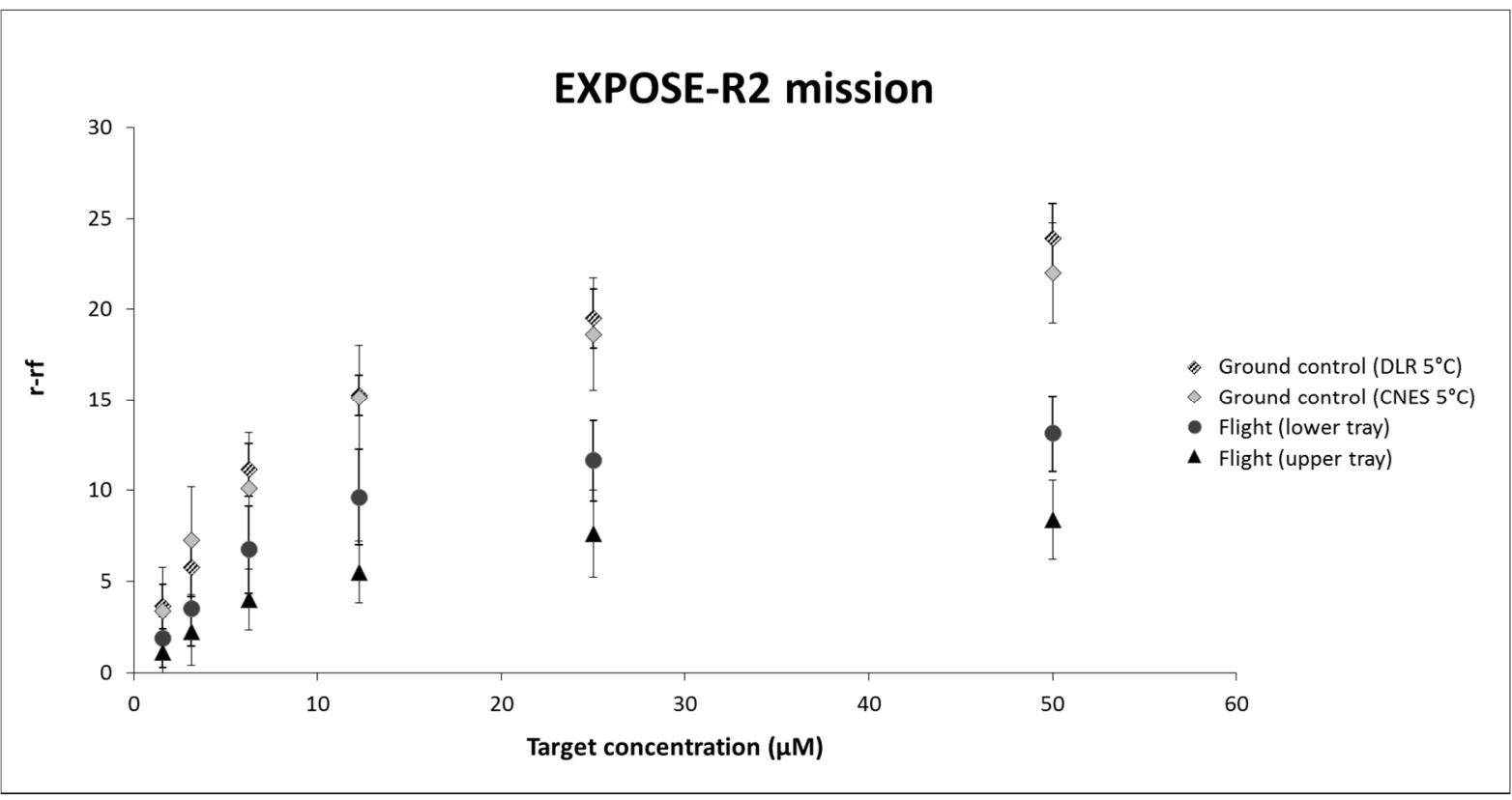

Figure 6 caption: Affinity curves for 49 merYm $3 \hat{\alpha}$ aptamer with additions of L-Tym obtained for controls and flight samples. The corresponding relative Kd values are given in Table 3. 
Table 1

\begin{tabular}{|c|c|c|c|c|c|c|c|}
\hline Date & \multicolumn{2}{|c|}{ Place } & $\begin{array}{l}\text { Particule } \\
\text { type }\end{array}$ & $\begin{array}{c}\text { Fluence } \\
\text { (particules } / \mathrm{cm}^{2} \text { ) }\end{array}$ & Energy & \multicolumn{2}{|c|}{ Irradiation duration } \\
\hline 04/27/2012 & $\begin{array}{l}\text { Istituto Nazionale } \\
\text { di Fisica Nucleare }\end{array}$ & Catania, Italy & ${ }^{12} \mathrm{C}$ & $F_{c}=2.10^{6}$ & $E_{c}=62 \mathrm{MeV} /$ nuc & $D_{c}=7 \mathrm{~min}$ & $\begin{array}{l}123 \\
724\end{array}$ \\
\hline 07/07/2011 & Institut Bergonié & Bordeaux, France & Electrons & $\begin{array}{l}\mathrm{F}_{\mathrm{e} 1}=3.10^{11} \\
\mathrm{~F}_{\mathrm{e} 2}=3.10^{10}\end{array}$ & $E_{e}=9 \mathrm{MeV}$ & $\begin{array}{l}\mathrm{D}_{\mathrm{e} 1}=70 \mathrm{~min} \\
\mathrm{D}_{\mathrm{e} 2}=7 \mathrm{~min}\end{array}$ & $\begin{array}{l}725 \\
726 \\
\end{array}$ \\
\hline 06/01/2010 & \multirow{2}{*}{$\begin{array}{l}\text { Centre de } \\
\text { Recherche du } \\
\text { Cyclotron }\end{array}$} & \multirow{2}{*}{$\begin{array}{c}\text { Louvain-la-Neuve, } \\
\text { Belgium }\end{array}$} & Neutrons & $\begin{array}{l}F_{n 1}=3.10^{13} \\
F_{n 2}=3.10^{12}\end{array}$ & $E_{n}=17 \mathrm{MeV}$ (mean) & $D_{n}=22 \min$ & $\begin{array}{l}727 \\
728\end{array}$ \\
\hline 03/06/2010 & & & Protons & $\begin{array}{l}F_{p 1}=3.10^{12} \\
F_{p 2}=3.10^{11}\end{array}$ & $\begin{array}{l}\mathrm{E}_{\mathrm{p} 1}=25 \mathrm{MeV} \\
\mathrm{E}_{\mathrm{p} 2}=50 \mathrm{MeV}\end{array}$ & $\begin{array}{l}D_{p 1}=1 \mathrm{~h} 40 \mathrm{~min} \\
D_{p 2}=10 \mathrm{~min}\end{array}$ & $\begin{array}{l}729 \\
730\end{array}$ \\
\hline
\end{tabular}

Table 1 caption Main experimental conditions for neutron, proton, electron and carbon ions irradiations. Subscript letters indicate the particle type and subscript numbers are used to differentiate the applied conditions. Units for fluences are in particles per $\mathrm{cm}^{2}$. Technical details have already been reported in Baqué et al. studies (Baqué et al., 2017). 
Table 2

\begin{tabular}{|c|c|c|}
\hline \multicolumn{3}{|c|}{ Experiments on ground-based particles accelerator facilities } \\
\hline Particle type & $\begin{array}{l}\text { relative } K_{d} \text { for irradiated samp } \\
\text { (fluence, energy, duration, repli }\end{array}$ & \\
\hline${ }^{12} \mathrm{C}$ & $1.01 \pm 0.15\left(\mathrm{~F}_{c} ; \mathrm{E}_{c} ; \mathrm{D}_{c} ; 3\right)$ & \\
\hline Electrons & $\begin{array}{l}1.09 \pm 0.22\left(\mathrm{~F}_{\mathrm{e} 1} ; \mathrm{E}_{\mathrm{e}} ; \mathrm{D}_{\mathrm{e} 1} ; 4\right) \\
0.99 \pm 0.20\left(\mathrm{~F}_{\mathrm{e} 2} ; \mathrm{E}_{\mathrm{e}} ; \mathrm{D}_{\mathrm{e} 2} ; 4\right)\end{array}$ & 742 \\
\hline Neutrons & $\begin{array}{l}1.19 \pm 0.35\left(F_{n 1} ; E_{n} ; D_{n} ; 3\right) \\
0.99 \pm 0.16\left(F_{n 2} ; E_{n} ; D_{n} ; 3\right)\end{array}$ & 744 \\
\hline Protons & $\begin{array}{l}0.88 \pm 0.21\left(F_{p 1} ; E_{p 1} ; D_{p 1} ; 3\right) \\
0.80 \pm 0.15\left(F_{p 1} ; E_{p 2} ; D_{p 1} ; 3\right) \\
0.93 \pm 0.18\left(F_{p 2} ; E_{p 1} ; D_{p 2} ; 3\right) \\
0.84 \pm 0.16\left(F_{p 2} ; E_{p 2} ; D_{p 2} ; 3\right)\end{array}$ & $\begin{array}{r}745 \\
746\end{array}$ \\
\hline
\end{tabular}

747

748 Table 2 caption: Relative dissociation constant values (relative $K_{d}$ ) (Eq. 2) derived from the

749 titration curves obtained for irradiated samples ( $n=3$ or 4$)$ after ground-based irradiation 750 experiments with at least $(n=3)$ reference samples. 
Table 3

\begin{tabular}{|c|cc|}
\hline \multicolumn{3}{|c|}{ Biochip in PSS experiment during the EXPOSE-R2 mission } \\
\hline \hline Sample type & relative $K_{d}$ (replicates) \\
\hline Ground control (CNES $5^{\circ} \mathrm{C}$ ) & $0.82 \pm 0.10(2)$ & 755 \\
\hline Ground control $\left(\mathrm{DLR} 5^{\circ} \mathrm{C}\right.$ ) & $1.00 \pm 0.10(2)$ & 756 \\
\hline Ground control (DLR $\Delta \mathrm{T}$ ) & $1.29 \pm 0.28(1)$ & 757 \\
\hline Ground control (DLR $\Delta \mathrm{T}+\mathrm{UV})$ & $0.93 \pm 0.20(2)$ & 758 \\
\hline Flight (upper tray) & $0.94 \pm 0.14(2)$ & 759 \\
\hline Flight (lower tray) & $1.07 \pm 0.21(2)$ & 760 \\
\hline
\end{tabular}

762

Table 3 caption: Relative dissociation constant values (relative $K_{d}$ ) (Eq. 2) derived from the titration curves issued from the ñBiochip in PSS experimentò during the EXPOSE-R2 mission. 